\title{
A perspectiva hedonista do elemento femme fatale: a contribuição da visualidade na construção da personagem Nelly Borden em Milano Calibro 9
}

\author{
Alexandre Rossato Augusti \\ Universidade Federal do Pampa, São Borja, RS, Brasil \\ ORCID: https://orcid.org/0000-0002-5924-8524

\section{Gilka Padilha de Vargas} \\ Centro Universitário Ritter dos Reis, Porto Alegre, RS, Brasil \\ ORCID: https://orcid.org/0000-0002-9408-5310
}

\begin{abstract}
Resumo
O trabalho objetiva, a partir da análise do filme Milano Calibro 9, abordar a perspectiva hedonista do cinema noir italiano. Elegese o elemento femme fatale como foco central de observação. Observa-se, prioritariamente, a visualidade da obra, buscandose regularmente os elementos concretos e visíveis de trabalho da direção de arte. A análise é conduzida por uma construção metodológica compreendida a partir de alguns pressupostos da Análise Fílmica, destacando-se, para tal, os autores Jacques Aumont e Michel Marie, e, Francis Vanoye e Anne Goliot-Lété, e também da proposição metodológica de Diane Rose. A pesquisa permite apontar e refletir sobre o modo como a femme fatale, em seu potencial hedonista, direciona as demais personagens e funciona como elemento fundamental para a condução da narrativa.
\end{abstract}

\section{Palavras-chave}

Análise fílmica. Cinema noir italiano. Direção de arte. Femme fatale. Hedonismo.

\section{Introdução}

A proposta deste trabalho é apresentar uma análise do filme Milano Calibro 9 (1972), com direção de Fernando di Leo, resultando-se neste artigo, como produto final do Curso de Especialização em Cinema. 0 referido filme é situado no gênero noir, e a análise 
tem foco na perspectiva hedonista do elemento femme fatale, com atenção especial para a visualidade da obra, observando-se, assim, mais particularmente os elementos concretos e visíveis de trabalho da direção de arte no contexto da narrativa ${ }^{1}$.

No que diz respeito a algumas especificidades do cinema noir italiano em relação, principalmente, ao norte-americano, que opera como referência mais comum para os filmes do gênero, destaca-se a percepção de Frezza (2012), para quem o cinema italiano dos anos 1950 e 1970 foi muito ousado, oferecendo uma linguagem mais moderna e, consequentemente, apresentando mais cenas de sexo. É desse modo que percebemos melhor no cinema italiano dessa época as cenas de nudez mais explícitas e apelos diversos de ordem sexual, seja em relação ao período anterior do gênero no contexto italiano ou em relação aos filmes noir ou neonoir de outros países no mesmo período.

Referindo-se aos períodos que abarcam as noções de gênero noir e neonoir, defendese que o cinema neonoir italiano surge a partir dos anos 90 (FREZZA, 2012; CAPRARA; CAZZOLINO, 2016), ao passo que os filmes neonoir estadunidenses são comumente datados a partir de 1958, considerando-se o período clássico do noir, sobretudo estadunidense, limitado entre 1941 e 1958, conforme Heredero e Santamarina (1996) e Silver e Ursini (2004).

O filme Milano Calibro 9 (1972) é compreendido, portanto, como pertencente ao noir clássico italiano, considerando-se, evidentemente, as particularidades de uma produção da década de 1970, principalmente no que tange à evolução da técnica, que agora permite o uso da cor e abordagens hedonistas que são possíveis para uma narrativa do gênero nesse período, e que, não eram permitidas anteriormente. É também com base nessas características que se objetiva analisar o filme a partir da visualidade ${ }^{2}$. A ênfase da análise se dará na figura da femme fatale, elemento central para que se compreenda o hedonismo no cinema noir.

\footnotetext{
${ }^{1}$ Essa pesquisa foi realizada com base na disciplina de Direção de Arte, ministrada pela Profa. Ma. Gilka Padilha de Vargas, no âmbito da Especialização em Cinema da Universidade Franciscana (UFN), entre os anos de 2018 e 2019 . As investigações aqui realizadas também se basearam na tese de doutorado, defendida no âmbito do Programa de Pós-Graduação em Comunicação Social (PPGCOM) da Pontifícia Universidade Católica do Rio Grande do Sul (PUCRS), denominada "Cinema noir: as marcas da morte e do hedonismo na atualização do gênero" por Augusti (2013), e nos estudos desenvolvidos por este em seu pós-doutorado no Programa de Pós-graduação em Comunicação e Informação (PPGCOM) da Universidade Federal do Rio Grande do Sul (UFRGS).

${ }^{2}$ Nesse âmbito, tem-se a visualidade salientando aspectos como enquadramentos, luz, cor e outras materialidades advindas da direção de arte.
} 


\section{0 hedonismo e a femme fatale no cinema noir}

Defende-se, no desenvolvimento deste texto, que é a femme fatale que sustenta de forma prioritária a perspectiva hedonista presente na narrativa da obra, através das alusões à beleza e ao sexo. Apesar do cinema noir ser mais comumente avaliado a partir da perspectiva do crime, destaca-se aqui justamente seu potencial de observação pelo enfoque do hedonismo, proposto pelos autores para salientar este olhar menos explorado.

Mencionam-se os sete elementos necessários para compor um filme noir, de acordo com Borde e Chaumeton (1958): (1) um crime; (2) a perspectiva dos criminosos, às vezes superando a da polícia; (3) uma visão invertida das tradicionais fontes de autoridade, acentuando a abordagem da corrupção policial; (4) alianças e lealdades instáveis; (5) a femme fatale; (6) violência bruta; (7) motivação e mudanças em complôs bizarros. Todos podem ser observados com maior ou menor ênfase na narrativa, mas destaca-se que serão recuperados aqui apenas nos momentos em que surgirem intersecções suas com o elemento femme fatale, obedecendo à orientação primeira quanto à ênfase da proposta.

A misoginia é facilmente observada nos filmes noir, devido ao tratamento oferecido às mulheres, principalmente no noir clássico, mas que também se estende ao neonoir, especialmente quando se verifica o destino da femme fatale na trama, geralmente punida e responsabilizada pelo infortúnio do protagonista. Entretanto, esta mulher, relegada ao papel de coadjuvante, é fundamental para o desenvolvimento da narrativa e determina o destino de muitas personagens.

Durante a Segunda Guerra Mundial, as mulheres foram encorajadas a trabalhar nas fábricas no lugar dos homens que estavam no front. Acumulavam, portanto, essa função àquela já habitual de cuidar da casa e da família. Tal emancipação de poder teria promovido o temor masculino quanto à competitividade, conforme Mattos (2001), para quem é decorrente dessa situação a misoginia observada no tratamento das personagens femininas.

Žižek (2009) estabelece uma fronteira para diferenciar a punição da femme fatale do noir clássica em oposição a do neonoir: enquanto a primeira é punida explicitamente, sendo destruída por ameaçar o poder masculino, o neonoir dos anos 1980 e 1990 permite de modo explícito que ela chegue ao triunfo, enquanto é seu parceiro quem é reduzido a quase nada, podendo até morrer. Entretanto, o autor defende que, no noir clássico, ainda que ocorra a destruição ou domesticação da femme fatale, a sua imagem sobrevive à destruição física, como elemento que efetivamente domina a cena; enquanto no neonoir referenciado, ela 
sobrevive materialmente, podendo ficar rica, mas não o faz como ameaça espectral, como ocorre com a primeira.

Milano Calibro 9 foi lançado em 1972 e, apesar de ser orientado enquanto noir clássico, conforme defesa dos autores indicados para situar o gênero no contexto italiano, o filme traz em sua abordagem um desfecho que o orienta para neonoir, já que o protagonista Ugo Piazza (personagem interpretada por Gastone Moschin) morre e a femme fatale Nelly Borden (Barbara Bouchet) sobrevive. Sobre esta, resta a dúvida se sobreviverá materialmente, no sentido de não ser punida com a prisão, não podendo usufruir de sua posição social, já que poderia ser envolvida no assassinato de Ugo ou mesmo considerada cúmplice no roubo do dinheiro. As características basilares que asseguram o perfil da femme fatale dos anos 1970 parecem ser mantidas no contexto italiano, o que se verifica nesta narrativa, quanto à maneira como ela seduz os homens. Há sugestão de um destino diverso para ela, entretanto.

Adiante, na análise, verificam-se o desenvolvimento da narrativa e de que modo ela direciona as personagens para seus destinos.

\section{Percepções sobre direção de arte no contexto fílmico e sua aproximação com a proposta do trabalho}

Considera-se a direção de arte no âmbito desta análise a partir da valorização do ambiente ${ }^{3}$, do figurino, da maquiagem e do cabelo, relacionados mais particularmente à femme fatale. Explora-se a interação desses elementos entre si para que contribuam para a construção dos sentidos do filme. Peter Ettedgui ao tratar a atividade da direção de arte pela perspectiva estética, defende que:

[...] consiste em destilar uma concepção visual a partir dos aspectos temáticos, emocionais e psicológicos que transpirem do roteiro. Esta concepção se torna o fator decisivo em todas as escolhas estéticas que concernem ao diretor de arte, tais como adereços, a massa e o volume dos ambientes. [...] as locações, as cores, tecidos e texturas de cada um dos decorados. Para dotar o filme de uma estética global, todos estes elementos devem harmonizar entre si e evocar uma atmosfera adequada à

\footnotetext{
${ }^{3}$ Vargas (2014) alerta para a possibilidade de utilização de termos diferenciados, já que os textos dos autores variam em relação ao lugar e à época. Quanto aos ambientes, em seu trabalho, encontrou-os colocados como cenografia, cenário, décor, decorado, set, place, space, lugar. Alerta-se que, no presente trabalho, algumas citações também apresentam variações dessa ordem.
} 
história e aos personagens. (ETTEDGUI, 20014, p. 9 apud VARGAS, 2014, p. 74, tradução de Vargas) ${ }^{5}$.

As personagens cujo foco analítico recai mais acentuadamente no filme em questão são observadas também de acordo com suas atitudes que, acrescidas dos elementos concernentes ao departamento de direção de arte, auxiliam a caracterizá-las no universo fílmico.

As atitudes comunicam as opiniões, os pontos de vista, e as diferentes posições que cada personagem assume em determinadas situações. Assim, têm o papel de definir as personagens, de conferir-lhes profundidade, ao mostrar o modo como encaram a vida. (SEGER, 2006, p. 48).

Conforme Jacob (2006, p. 37), “a Direção de Arte engloba os campos de trabalho que no cinema conceituam, realizam e apresentam soluções plásticas capazes de atender as demandas estéticas do filme.". A autora os identifica como sendo o figurino, a cenografia, a caracterização e, algumas vezes, os efeitos especiais. A partir dessa explicação, reporta a sua compreensão sobre o papel da direção de arte: “[...] criar para o filme uma imagem visual expressiva, carregada de valores plásticos abrangendo os espaços ${ }^{6}$ construídos, e a caracterização dos personagens." (JACOB, 2006, p. 37). Um panorama mais completo da direção de arte pode ser oferecido ainda por Elizabeth Motta Jacob, ao explicar:

A criação da Direção de Arte em alguns casos pode ser entendida enquanto numa transposição das intenções do Diretor e dos dados dramatúrgicos em imagens, dialogando com os demais elementos constituintes da imagem cinematográfica. A Direção de Arte se revela enquanto uma linguagem visual específica, um elemento de construção visual do filme em sua composição plástica, valorizado pela luz e pelo registro efetuado pela câmera e, portanto, da própria imagem cinematográfica. Para isso, a Direção de Arte pode atuar de diferentes modos, obtendo efeitos e objetivos distintos em cada um deles, sem abster-se jamais de viabilizar as tomadas propostas pelo Diretor, dando a este, liberdade de ação e conforto espacial. (JACOB, 2006, p. 37).

\footnotetext{
${ }^{4}$ ETTEDGUI, Peter. Diseño de producción y dirección artística. Barcelona: Océano, 2001. Apud Vargas (2014).

${ }^{5}$ No original: “[....] consiste en destilar una concepción visual a partir de los aspectos temáticos, emocionales y psicológicos que rezuma el guión. Esta concepción se convierte en el factor decisivo en todas las elecciones estéticas que atañen al diseñador, tales como el atrezo, la masa y volumen de los decorados. [...] las localizaciones, los colores, telas y texturas de cada uno de los decorados, etcétera. Para dotar al film de una estética global, todos estos elementos deben armonizar entre sí y evocar una atmósfera adecuada a la historia y los personajes".

${ }^{6}$ Refere-se aqui a espaços concretos e materiais. Vargas (2014) defende que o espaço, no caso do cinema, é primeiramente concreto. E traz várias nomenclaturas referentes a este espaço: “[...] espaço arquitetônico, espaço cenográfico, cenário, espaço cênico, espaço concreto, espaço físico, espaço cinematográfico, espaço volumétrico, decorado, etc." (Vargas, 2014, p. $54)$.
} 
É nesse sentido que se direciona neste trabalho a observação dos ambientes e da caracterização visual das personagens principais que neles transitam.

Jacob (2006), ao mencionar a palheta cromática, informa que ela pode variar nos diferentes núcleos ou ser a mesma para o conjunto da obra, bem como pode ser escolhida uma palheta particularmente a uma determinada personagem, seja no que se refere aos seus cenários como aos seus figurinos. Essa observação é importante para que observemos a femme fatale e sua interação com os demais personagens a partir dos cenários em que atua. Aponta-se, ainda, conforme a autora, um delineamento sobre possibilidades expressivas da cor e que também será recuperado adiante:

[...] a cor é um elemento extremamente expressivo, tendo grande valor dramático. Seu uso pode ser subliminar, metafórico ou explícito. Ela pode ser usada como um meio de fortalecer a informação visual por seu caráter eminentemente emocional. (JACOB, 2006, p. 43).

Sobre o cenário, alude-se a Bazin (1949), que no texto $O$ cenário é um ator ${ }^{7}$, publicado no jornal Cine-Club em dezembro de 1949, conclui, a partir da observação do filme Trágico amanhecer (Le jour se lève, 1939), de Marcel Carné: "Vemos como o cenário coopera tanto quanto a atuação do ator para justificar situações, explicar o personagem e estabelecer a credibilidade da ação."8 (BAZIN, 1949, p. 6-7, tradução nossa). Aumont e Marie (2004) elogiam o cuidado de André Bazin no que diz respeito a observações do último sobre os elementos dos cenários do referido filme:

0 autor prossegue a sua 'espécie de inquérito à Sherlock Holmes para reconstituir a vida e a personagem de Gabin' através de outros indícios [aponta vários em sua interpretação] fornecidos pelo cenário do quarto, a fim de responder à pergunta 'Quem é Gabin?', 'O que representa ele enquanto mito?' (AUMONT; MARIE, 2004, p. 27).

Não se quer aqui sugerir a possibilidade de proceder a uma análise tão completa e complexa como a realizada por André Bazin, mas dar uma dimensão do potencial expressivo, dramático e simbólico dos elementos de direção de arte observados e apontar o quanto estes são fundamentais para esclarecer as situações da narrativa, com base também

\footnotetext{
${ }^{7}$ No original: "Le décor est un acteur".

${ }^{8}$ No original: "Nous voyons comment le décor coopère tout autant que le jeu de l'acteur à justifier les situations, à expliquer le personnage et à fonder la crédibilité de l'action".
} 
na atuação das personagens. No que tange aos figurinos, recupera-se ainda Elizabeth Motta Jacob, para quem:

\begin{abstract}
Vestir implica em se proteger, responder a rituais, transmitir uma determinada imagem, estabelecer vínculos sociais, além do desejo de beleza. A roupa permeia as relações entre a pessoa e o seu entorno, se constituindo em um sistema de representação. Ela altera a aparência e a forma do corpo definindo silhuetas específicas ao longo do tempo. 0 uso da roupa se patenteia numa manifestação sociocultural, a pessoa que a usa expressa a sua identidade e sua inserção em um determinado meio. Este desejo de expressão, em alguns casos implica em intervenções diretas e definitivas sobre o corpo tais como tatuagens, escoriações, piercings, alargadores de orelhas etc... (JACOB, 2006, p. 44-45).
\end{abstract}

A autora considera, assim, o vestir como toda a ornamentação, incluindo penteados, adereços etc. E destaca, a partir disso, alguns aspectos sobre figurinos:

A elaboração de figurinos para o cinema se baseia nestas representações, tendo como objetivo comunicar plasticamente o universo dos personagens criados. As artes do espetáculo se servem das roupas e dos adornos em seu significado simbólico. Sua criação emerge de uma ideia definida pelos aspectos dramatúrgicos que pretende evidenciar. A roupa, como figurino, além de plástica deve se adequar à estética proposta pelo espetáculo, sendo verossímil, alegórica etc., conforme as necessidades expressas na obra. (JACOB, 2006, p. 45).

Considera-se o ambiente a partir de uma complexidade de elementos que dão o tom da narrativa e caracterizam as personagens, devido, inclusive, a ser esse o foco desta análise. Desse modo, orienta-se por Vargas (2014), com o propósito de trazer mais consistentemente tal compreensão sobre o ambiente de um filme:

[...] não se reduz [o ambiente] a um espaço físico e concreto necessário às ações e à evolução da narrativa. Trata-se de um universo construído pela direção de arte com seus elementos de trabalho - arquitetura, paisagem, cenografia, móveis, objetos, cores, texturas -, a fim de criar sentidos, abrangendo aspectos vinculados a questões psicológicas, sociais, culturais, econômicas, adequando-o à personalidade e à história do personagem; isto é, impregnando-o com a personalidade e a história de quem supostamente o habita. Ele deve ser concebido de modo que justifique situações, explique atitudes, caráter e emoções, constituindo-se em fator de credibilidade quanto às ações. (VARGAS, 2014, p. 91).

De acordo com Junqueira (2017, p. 153), “o ambiente é não apenas o espaço em que se passam as ações do filme como também um conjunto de mensagens que contribuem para 
a construção de uma personalidade e de uma situação [...]”. É relevante observá-lo nesse sentido em Milano Calibro 9, principalmente porque o ambiente e suas variações são determinantes para que se percebam as estratégias da femme fatale para seduzir suas vítimas e conduzi-las de acordo com seus objetivos.

\section{Metodologia}

A análise do filme Milano Calibro 9 (1972) é conduzida por uma construção metodológica compreendida a partir de alguns pressupostos da Análise Fílmica, destacandose, para tal, os autores Jacques Aumont e Michel Marie (2004) e Francis Vanoye e Anne Goliot-Lété (1994), e também da proposição metodológica de Diane Rose (2002). Os primeiros autores, com base na Análise Fílmica, ressaltam a ideia de extrair do filme certos materiais para que sejam avaliados esses recortes, permitindo-se sua análise em separado e não mais em conjunto com os demais materiais da obra, possibilitando-se descobrir o que não seria possível quando tomado o filme como um todo. Parte-se, no caso deste trabalho, dessa noção primordial. Destaca-se que esses materiais são selecionados conforme as pertinências da análise, que destaca o hedonismo amparado pela figura da femme fatale. Após a seleção, esses elementos serão descritos e interpretados, tendo em vista os referenciais teóricos e metodológicos considerados.

A proposta de Rose (2002), sobre análise de imagens em movimento, tem base em quatro fases: seleção, transcrição, codificação e tabulação. Entretanto, permitem-se adaptações para privilegiar a análise de acordo com as especificidades de cada pesquisa. Neste caso, limita-se à observação das duas primeiras fases, entendendo-se que tal limitação favorece a compreensão de algumas subjetividades decorrentes da narrativa complexa e do enfoque já apontado. Codificar e tabular talvez restringisse e tornasse menos flexível o processo interpretativo. A seleção se refere, resumidamente, à separação do conteúdo a ser estudado, conforme se destacou na perspectiva da Análise Fílmica. A transcrição traz a descrição do material selecionado e é realizada em duas colunas. Na proposta de Rose (2002), a da esquerda descreve o aspecto visual da história e a da direita é uma transcrição literal do material verbal. No presente trabalho, apresenta-se a coluna da esquerda contendo os elementos concretos e visíveis de trabalho da direção de arte que compõem o 
visual do filme ${ }^{9}$ e a da direita, uma transcrição literal dos diálogos e banda sonora, tendo-se atenção a esta última quando sua observação for mais colaborativa para os objetivos da análise. Compreende-se, no caso desta análise, que observar os diálogos e a banda sonora é também importante para que se valorizem, inclusive, os aspectos da visualidade de acordo com a proposta do trabalho. Assim, intensificam-se as possibilidades de compreensão da narrativa, já que o foco da análise é justamente a observação da femme fatale, em seus potenciais hedonistas, e o modo como ela direciona a narrativa.

Selecionam-se três sequências para a observação da visualidade, com foco no elemento femme fatale, e que objetivam demonstrar o processo de sedução dela em relação àqueles que deseja vitimar. Todas as sequências estão relacionadas a ambientes que auxiliam na construção desta personagem e que têm papel importante em seu funcionamento na narrativa. A primeira mostra a apresentação da femme fatale em seu ambiente de trabalho (como ela é mostrada no bar, no espaço em que seduz e trabalha para seu sustento com vistas à ascensão social). A segunda mostra como ela quer ser vista, em sua casa, trazendo uma mulher sofisticada em um ambiente adequado para viver esse estilo, e onde completa a sedução do homem. E, na terceira, tem-se, ainda, seu ambiente doméstico refinado, mas também onde ela se revela, definitivamente, atacando sua vítima.

\section{Análise}

Milano Calibro 9 (1972) é um filme dirigido por Fernando di Leo, baseado no livro homônimo do escritor Giorgio Scerbanenco, que contém 22 contos noir, publicados em 1969. Francesco Cuppini assina a cenografia e figurino do filme, considerando-se, portanto, sua função atrelada à direção de $\operatorname{arte}^{10}$.

O filme desenvolve a história de Ugo Piazza (personagem interpretada por Gastone Moschin), em Milão, sendo perseguido por antigos comparsas no crime e obrigado a retornar às antigas atividades, tão logo é liberto da prisão, onde permaneceu por três anos. Recai sobre Ugo a responsabilidade pelo desaparecimento de 300 mil dólares de um golpe.

\footnotetext{
9 Considerando-se que o visual também envolve enquadramentos, luz atmosfera e outros elementos, destaca-se que a análise também invade em alguns momentos o departamento de fotografia. Salienta-se que a visualidade é construída pela direção, a direção de fotografia e a direção de arte, com esta última visando a concepção da materialidade dos elementos do filme. Esta coluna também pode trazer descrições da ação que colaboram para a compreensão da narrativa, de acordo com os objetivos do trabalho.

10 Ocorre também neste caso a possibilidade de utilização de termos diferenciados para designar função semelhante ou equivalente àquela exercida por profissionais nominados diversamente em outros contextos de produção.
} 
Ele envolve-se novamente com Nelly Borden, que sabe seduzi-lo e utiliza o ambiente de trabalho e o ambiente doméstico para executar seus planos.

Milano Calibro 9 é um filme noir já atualizado no que diz respeito aos recursos da técnica, ressaltando-se aqui o uso da cor, trazendo ainda algumas renovações que dizem respeito ao que já se permite mostrar em uma produção da década de 1970, destacando-se aqui as alusões mais evidentes ao sexo. Com ritmo mais acelerado e trilha sonora mais dinâmica, potencializa-se também a dinamicidade da narrativa. 0 filme é muito violento, evidenciando algumas agressões graves, inclusive em mulheres. 0 sangue, que agora aparece vermelho, impacta mais. Também já há ganhos em relação à tecnologia, com efeitos mais reais em algumas cenas (em comparação ao noir tradicional, preto e branco), como explosões, por exemplo.

O filme traz cenas com mulheres nuas, com seios bem visíveis ou com a femme fatale dançando apenas com roupas íntimas. Aparecem ainda cenas de sexo e não apenas a insinuação disso. 0 corpo das mulheres é mostrado nu, ainda que discretamente, mas com exceção dos seios, que aparecem bem. Há uma exploração mais notória da nudez, com apelo hedonista mais evidente do que geralmente se verifica no gênero em filmes de períodos anteriores.

A descrição da sequência a seguir apresenta elementos que permitem perceber de modo mais elucidativo essas observações e outras, caras aos objetivos da análise ${ }^{11}$.

\subsection{Primeira sequência: a apresentação da femme fatale $e^{12}$}

Quadro 1 - A apresentação da femme fatale

\begin{tabular}{|c|c|}
\hline $\begin{array}{l}\text { Elementos que compõem o visual do } \\
\text { filme }\end{array}$ & $\begin{array}{c}\text { Transcrição literal dos diálogos e banda } \\
\text { sonora }\end{array}$ \\
\hline $\begin{array}{l}\text { No que se refere ao enquadramento, } \\
\text { em relação à altura do ângulo, tem-se um } \\
\text { contra-plongée, evidenciando a imagem } \\
\text { de Nelly dançando em um bar. } \\
\text { Explora-se todo o corpo da femme } \\
\text { fatale, de biquíni sobre uma mesa. O traje } \\
\text { tem muitas cores e brilhos. Planos } \\
\text { fechados permitem observar a maciez e o }\end{array}$ & Música com ritmo dançante. \\
\hline
\end{tabular}

\footnotetext{
11 Para melhor compreensão, apresentamos apenas o quadro referente à primeira sequência, evidenciando-se, portanto, um caráter ilustrativo de como procedemos o método.

12 Inicia-se em aproximadamente 36 minutos e 20 segundos de filme.
} 
loiro claríssimo do cabelo de Nelly.

0 cenário traz prioritariamente $\mathrm{o}$ vermelho, seguido do azul. 0 piso é vermelho. Há também abajures e sofás sofisticados, com tons amarelo ou bege. Os tecidos presentes nos elementos do cenário têm texturas macias. Aparecem diversos frequentadores do local, com muitos deles atentos à performance da dançarina.

Ugo aparece no local, avista Nelly de longe e senta-se ao balcão do bar. Conversa com o garçom e ambos olham para ela.
Garçom: - Como está, Ugo?

Ugo: - Bem.

Garçom - Ouvi que saíste.

Ugo: - Ontem.

Garçom: Ela sempre pergunta de ti.

Ugo: - Me traga uma taça.

Garçom [ordenando ao garçom Luca]: Uísque com água, sem gelo. $\log 0$.

Garçom [referindo-se à Nelly]: — Sai

Mesma música dançante.

Luca, outro garçom, com uniforme cujo paletó é vermelho, traz a bebida. É apresentado a Ugo. Luca sorri a Ugo, que bebe.

Algumas pessoas dançam.

Close em Ugo fumando.

Homem de óculos, um dos criminosos do bando do Americano (chefe do grupo criminoso, a quem deveria ser entregue 0 dinheiro desaparecido) sinaliza para Ugo, evidenciando estar presente.

Nelly encerra sua apresentação.

Homem de terno e cabelos escuros, do mesmo bando, a ajuda a descer da mesa e fala com ela.

Ela busca Ugo com os olhos.

Close no rosto de Nelly, que sorri e corre em direção a Ugo.

Homem de terno e cabelos escuros ameaça se levantar. Homem de óculos o impede e lhe fala.

Nelly, sorridente, de frente para Ugo e, inicialmente, apoiada no balcão.
Luca: - Aqui, Sr. Piazza.

Garçom [anônimo]: - Olhe quanto cresceu Luca!

Mesma música.

Mesma música ambiente.

[falando para Nelly]: - Ugo está aqui.

Homem de óculos [falando ao Homem de terno e cabelos escuros]: - Tranquilo.

Encerra-se a música agitada, sendo substituída por uma música ambiente calma e relaxante.

Nelly: - Ugo. Pensava que tomaria o primeiro voo para Beirute.

Ugo: - Como está, Nelly?

Nelly: - Com três anos a mais. Sabe o Americano que saiu? 


\begin{tabular}{|c|c|}
\hline & Ugo: - Voltei a trabalhar para ele. \\
Nelly: - Não acredito! Bem, isso é seu \\
problema. Saiu ontem. Por que demorou tanto \\
em vir? Por quê? Responda-me. \\
Ugo: - Somente agora me dei conta que \\
estou vivo. Ontem não o sabia. E então... \\
Mesma música ambiente calma.
\end{tabular}

Fonte: Elaborado pelos autores.

É a primeira vez que se vê a femme fatale, Nelly Borden, interpretada pela bela Barbara Bouchet. Ela aparece dançando, alegre, vibrante, sensualmente, sobre a mesa do bar, exibindo uma performance muito insinuante e erótica, ao mover seu corpo com agilidade ao embalo da música com ritmo veloz e provocante (figura 1). 0 ângulo da câmera em contra-plongée a apresenta empoderada, permitindo-se, já em sua apresentação, perceber o potencial e periculosidade desta mulher linda e sedutora. 
Figura 1 - Fotograma de Nelly dançando sobre a mesa.

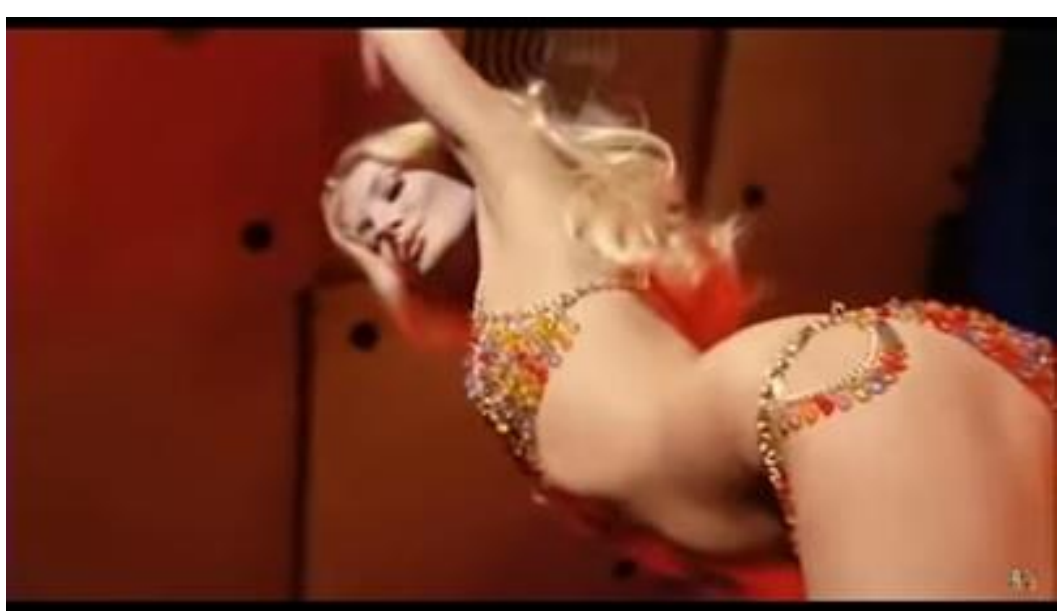

Fonte: Milano Calibro 9 (1972).

O vermelho, abundantemente utilizado no cenário, faz alusão à sedução e talvez antecipe o perigo que decorre do envolvimento com essa mulher, já que também evoca a referência ao sangue (figura 2). Nelly parece feliz ao encontrar o protagonista Ugo. Entretanto, percebe-se que Ugo está vigiado e as aparições de Luca (Salvatore Arico) também colaboram para aludir à alguma relevância do garçom na narrativa (figura 3). 0 paletó vermelho do último também pode aludir a um envolvimento amoroso com Nelly ou ao perigo que representa.

Figura 2 - Fotograma do bar onde Nelly se apresenta.

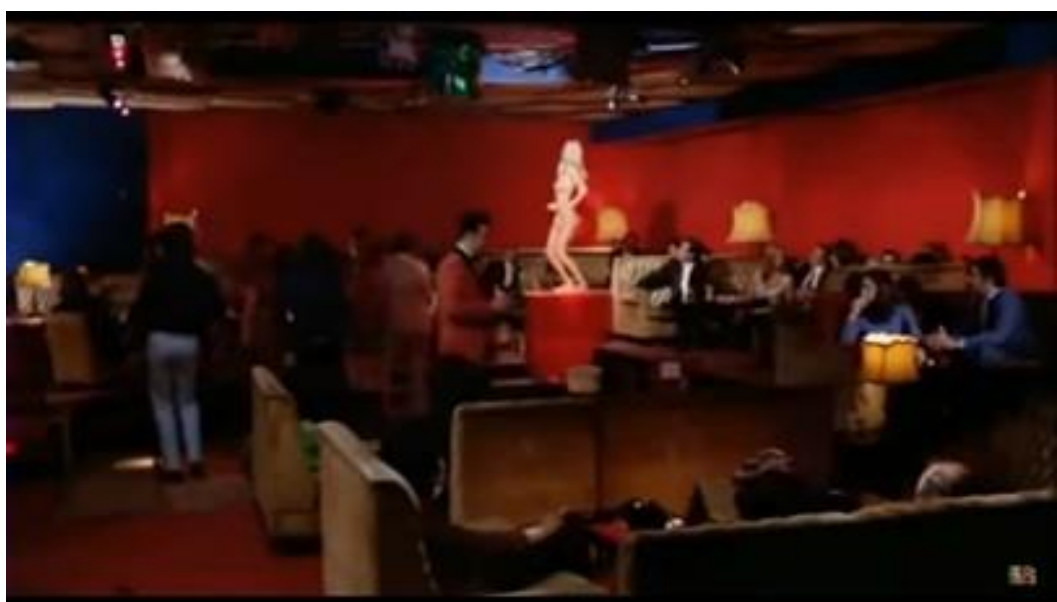

Fonte: Milano Calibro 9 (1972). 
Figura 3 - Fotograma de Nelly com Ugo, no balcão, vigiados por Luca.

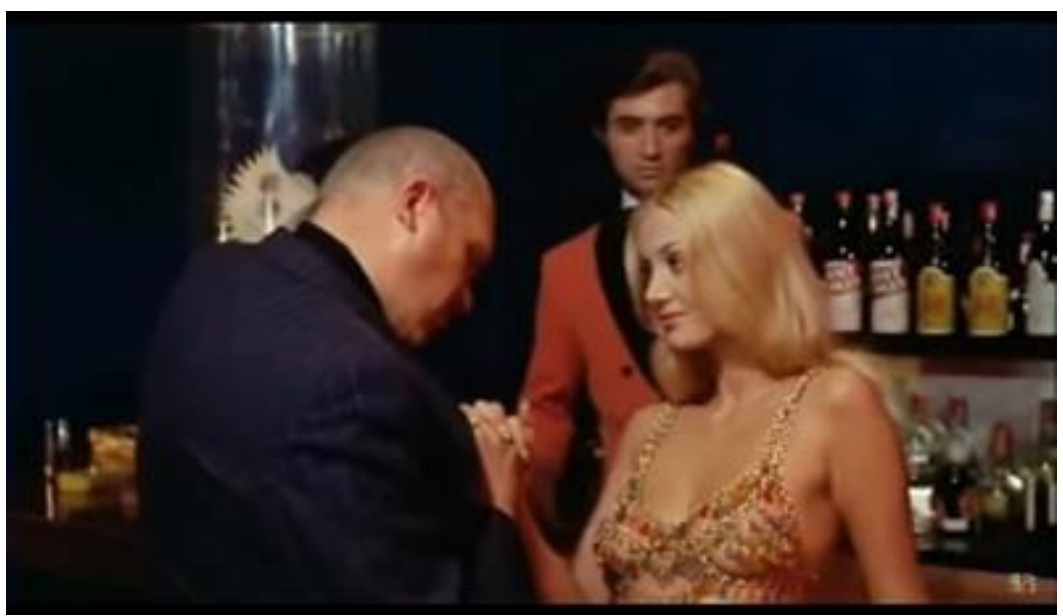

Fonte: Milano Calibro 9 (1972).

Nelly, embora sua transformação, apresentando-se feliz ao perceber Ugo, deixa transparecer sua teoria de que ele está de posse dos 300 mil dólares, pois a primeira frase que a ele dirige é uma menção a sua expectativa de que ele fosse para Beirute, o que mais adiante (no carro) ela deixará claro, pois imagina que ele assim o faria para aproveitar o dinheiro. Também o cobra por não ter vindo vê-la antes, já que estava liberto há um dia.

Adiante, ela o convida para ir a sua casa e não permite que o mesmo recuse antecipando qualquer palavra negativa ao lhe tapar a boca.

No caminho, é ela quem dirige, mostrando a independência própria da femme fatale. Nelly acredita que Ugo realmente tenha o dinheiro ou afirma essa certeza através da provocação, quando pergunta por que ele não vai a Beirute gastar o dinheiro. Assim, poderia ouvir uma confissão, o que não se confirma, pois recebe uma insinuação de negativa, e um apontamento de decepção por parte de Ugo quanto ao julgamento da mulher sobre ele. Entretanto, ela dá sequência ao plano de sedução e o leva para seu apartamento.

\subsection{Segunda sequência: a femme fatale seduz definitivamente ${ }^{13}$}

No hall do prédio em que mora Nelly, veem-se muitas plantas (figura 4). Algumas conhecidas no Brasil pelo nome comigo-ninguém-pode e outras por costela-de-Adão. Em algumas regiões do mundo, as primeiras são reconhecidas por espantarem mau-olhado ou maus espíritos, além de serem venenosas, já aludindo a uma característica da femme fatale. As plantas costela-de-Adão podem sugerir o vínculo da femme fatale à figura de Eva, que

${ }^{13}$ Inicia-se em aproximadamente 41 minutos e 30 segundos de filme. 
experimentara o fruto proibido, oferecendo-o também a Adão, o que ocasionou sua expulsão do Paraíso. Nesse caso, teríamos também assim uma construção que responsabiliza a mulher pela derrocada do homem. Nelly seria, então, responsável pelo infortúnio de Ugo, que sucumbiria devido ao seu envolvimento com ela. São elementos do cenário caros à construção da visualidade e que apontam para o perigo que envolve esse tipo de mulher. As sombras da planta e do casal no hall e corredor do prédio evocam a atmosfera noir. 0 ambiente, apesar de refinado e elegante, é frio (inclusive pela escassez de luz), assim como o apartamento de Nelly (este, porém, bem iluminado, com propósito de fazer ver claramente a decoração), o que evoca a frieza da femme fatale. Ela chega ao seu prédio toda vestida de preto, numa alusão importante ao estilo noir, sugerindo perigo também por essa referência, mas tal sobriedade não a impede de se mostrar sempre sensual, o que as botas de cano longo e a parte das pernas vistas nuas permitem evocar.

Figura 4 - Fotograma de Nelly e Ugo, no hall do prédio, cheio de plantas e com luz escassa.

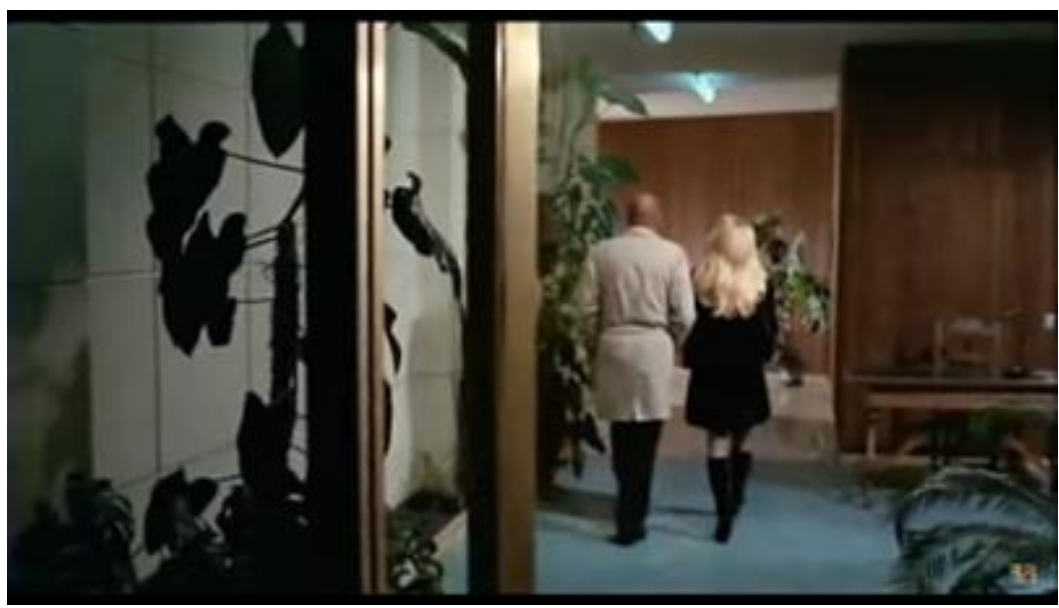

Fonte: Milano Calibro 9 (1972).

O apartamento da femme fatale Nelly, ainda que elegante e refinado, tem decoração em preto e branco, ao estilo contrastante característico do noir (figura 5). É uma referência importante para situar o filme no gênero e rememorar sua atmosfera negra, estabelecida também pela ausência de outras cores. É um relevante aspecto da visualidade, que confere ao ambiente a referida atmosfera, permitindo compreender as personagens que ali interagem, sobretudo caracterizando a femme fatale em seu habitat. 
Figura 5 - Fotograma do apartamento de Nelly com os pássaros aprisionados (à direita).

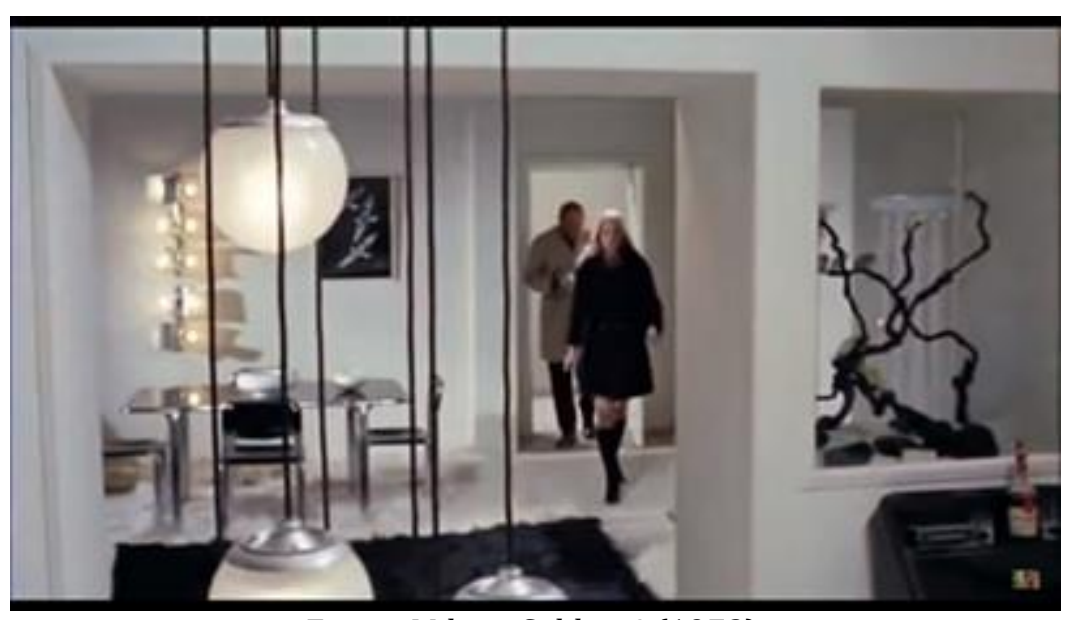

Fonte: Milano Calibro 9 (1972).

Na decoração veem-se objetos com formas sinuosas como se fossem galhos secos de uma árvore, a exemplo de braços negros, enrugados e magros que se projetam para cima. Tais formas, cor e textura são sugestivas. Pode-se pensar em plantas parasitas que se prendem a uma base, da qual sugam a força para sobreviverem, ideia também vinculada à característica funcional da femme fatale. Também fazem alusão à natureza morta, inclusive porque contêm flores negras e secas. E ainda evocam a ideia das projeções de sombras do cinema expressionista alemão, que inspirou o noir, assim como as próprias sombras das plantas e de algumas personagens. É uma decoração rica em elementos de design, reafirmando o estilo e refinamento da mulher. Após trocar as roupas, aparece vestindo branco e preto. Sempre muito elegante, apresentando, porém, decote e fenda no vestido, um recurso do vestuário muito provocante.

Os sons de pássaros nesta sequência já remetem à metáfora que ficará cada vez mais clara em outras cenas (inclusive a sequência final, que será trabalhada adiante). São observados pássaros vivos ao redor dos galhos da decoração que estão na parede do quarto. É uma espécie de gaiola de vidro que se confunde à parede, um tipo de viveiro estilizado. São vários pássaros, quase que como uma coleção, podendo fazer alusão à coleção de homens que passam pela vida dela e contribuem para sua ascensão social. Nelly já admitira a Ugo que teve vários homens, mas que nunca quis um fixo, sugerindo que o quer deste modo. Os pássaros aprisionados permitem estabelecer uma relação com os homens que colecionou e dos quais se desfez. Ela propõe a Ugo que fiquem juntos se ele desejar, o que, provavelmente, faz parte de seu plano de ficar com o dinheiro que acredita estar na posse dele. 
Ugo percebe, através de seu apartamento, que a vida dela agora é de um nível social superior. Comenta sobre isso e ela procura se justificar, referindo-se à solidão que sentiu sem ele e vai até a cama, desviando sua atenção enquanto tenta seduzi-lo. Mas ele diz não cobrar nada dela e que três anos é muito tempo. Ainda assim, vai questioná-la sobre outros homens. Os cigarros são comuns nos filmes noir, apontando momentos de tensão ou mesmo evocando o erotismo a partir de seu potencial fálico. Aqui parece funcionar para ambas as situações. A música romântica traz ganhos à ambientação, auxiliando na construção de uma atmosfera de sedução. Na narrativa, colabora para a elaboração de sentidos que adiantam ao espectador o provável envolvimento sexual do casal num futuro imediato.

Quando o casal se beija na cama e transa, é mostrado em primeiríssimo plano, com objeto decorativo metálico, fora de foco, entre eles e a câmera (figura 6). Não aparecem os seios da femme fatale, ainda que se perceba a nudez do casal. A um certo ponto, as imagens do objeto e do casal se fundem, num jogo que propõe confundir, da mesma forma que a trama da narrativa funciona. 0 brilho é outra referência do ambiente sofisticado e combina com a figura elegante da mulher, seja decorrente de suas características físicas, que correspondem a um padrão clássico de beleza (loira, com cabelos longos e sedosos, alta e com olhos azuis), seja pelo seu vestuário. Ainda que no ambiente doméstico, sua maquiagem é bem perceptível. Apresenta a mesma que usara no bar. De bom gosto, não atrevida, mas realçando sua beleza com sofisticação.

Figura 6 - Fotograma do casal fazendo sexo, com imagem de Ugo misturada à decoração.

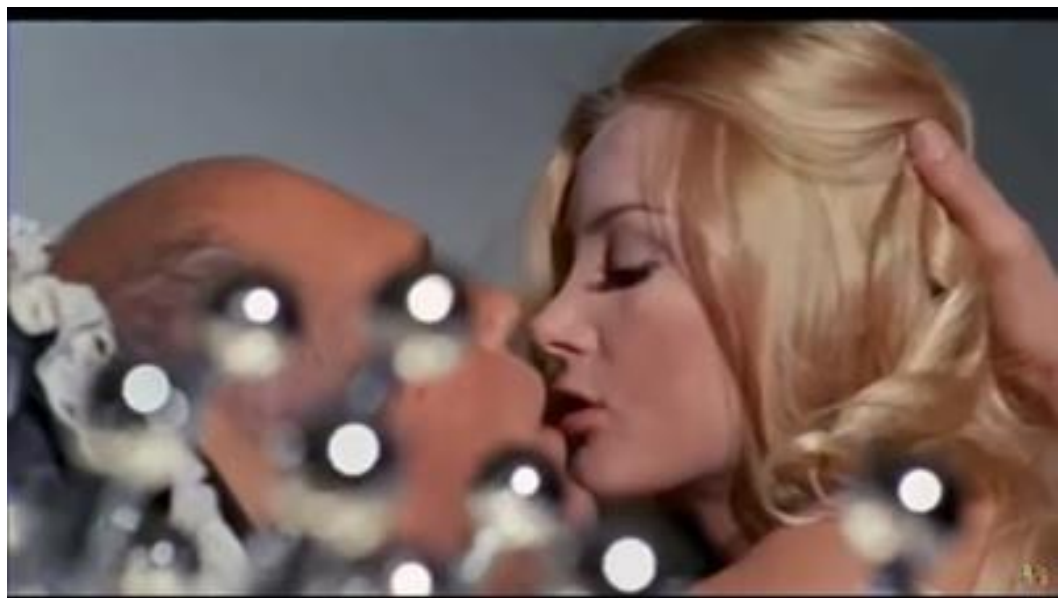

Fonte: Milano Calibro 9 (1972). 


\subsection{Terceira sequência: a revelação da femme fatale ${ }^{14}$}

Ugo sai da delegacia, após ser liberado, sendo que não foi envolvido no massacre ocorrido e do qual efetivamente participou, no qual morreram o Americano e muitos de sua gangue. Ele se dirige ao apartamento de Nelly, que é mostrada primeiramente através da decoração de galhos onde estão os pássaros aprisionados. Há novamente uma referência do que ela pode fazer com os homens: enjaulá-los, submetê-los a ela, dominá-los. Nessa ocasião, tanto Ugo, que interage com Nelly ao telefone, quanto Luca, que está fisicamente presente no ambiente, podem ser reportados à condição de homens seduzidos e manipulados por ela.

A femme fatale está com a sacola roubada por Luca do último golpe promovido pelo Americano e que contém 30 milhões de liras, além de uma arma. Ela fala com Luca enquanto Ugo vai ao seu apartamento. Luca aparece com a jaqueta vermelha, que permite identificá-lo como aquele que vigiou Ugo em outra cena e roubou a sacola com dinheiro. 0 vermelho, aludindo à paixão, também pode apontar uma ligação de Luca com Nelly, já que o primeiro provavelmente é apaixonado por ela, o que é sugerido na narrativa por prestar serviço à femme fatale, como se evidencia ao final. Também faz remissão à periculosidade de Luca, sendo que o último já fez e provavelmente ainda fará vítimas, em se reportando à cor do sangue, igual à da jaqueta.

Quando Nelly recebe Ugo, o som dos pássaros cantando evocam sua condição, propondo-se a analogia com os homens que a femme fatale coleciona e "aprisiona", através de sua performance hedonista, fortemente alicerçada em sua beleza e seu apelo de ordem sexual. Este som é quase constante no ambiente, sendo interrompido apenas em momentos em que a ação exige atenção a efeitos ou trilhas da banda sonora, ou mesmo diálogos, por exemplo. Visa, portanto, evocar essa sugestão quanto à femme fatale. Os ramos de galhos secos, negros, com flores remontando a natureza morta, também funcionam como um agouro para as personagens.

No momento em que Ugo mostra a bolsa com dinheiro a Nelly, antes mesmo dela ordenar a Luca que atire em Ugo, a femme fatale se transfigura de mulher doce e apaixonada para a interesseira e fria (figura 7). As expressões da face evidenciam essa mudança. Ela veste calça preta e blusa branca, desta vez com casaco verde. Um conjunto com uma cor mais viva propõe mais alegria e talvez esperança (verde), seja para ela, que pretende obter o dinheiro de Ugo, quanto para ele, que havia decidido fugir com ela.

14 Inicia-se em aproximadamente 1 hora, 31 minutos e 35 segundos de filme. 
Figura 7 - Fotograma da femme fatale, divertindo-se e revelando-se após ver o dinheiro de Ugo, com pássaros ao fundo.

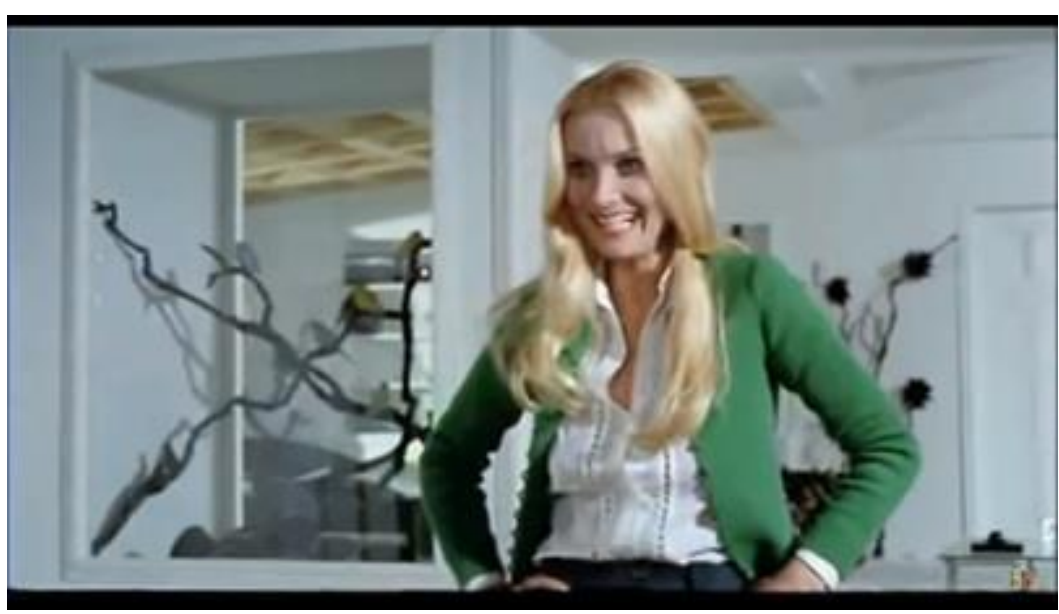

Fonte: Milano Calibro 9 (1972).

Conforme Chevalier e Gheerbrant (1992), o verde é uma cor tranquilizadora. Também "é a cor da esperança, da força, da longevidade [...]." (CHEVALIER, GHEERBRANDT, 1992, p. 939). Chevalier e Gheerbrant (1992) apontam o vermelho como uma cor masculina (cor da jaqueta de Luca) e o verde como uma cor feminina. Recuperando o pensamento chinês, trazem a noção do yin como masculino e vermelho e do yang como feminino e verde. Também mencionam que se pode pensar que a cor verde esconde um segredo: “[...] simboliza um conhecimento profundo, oculto, das coisas e do destino." (CHEVALIER, GHEERBRANDT, 1992, p. 941). Esta última alusão à cor pode remeter à ambiguidade da femme fatale, que se mascara de boa moça, enquanto normalmente sabe mais do que revela, antecipando e alterando o destino de algumas personagens. Adiante, Chevalier e Gheerbrant (1992, p. 941) acrescentam que "o verde possui uma força maléfica, noturna, como todo o símbolo feminino.". E completam: "o verde conserva um caráter estranho e complexo, que provém da sua polaridade dupla: o verde do broto e o verde do mofo, a vida e a morte. É a imagem das profundezas e do destino." (CHEVALIER, GHEERBRANDT, 1992, p. 943). 0 caráter também estranho e complexo da femme fatale parece encontrar respaldo em diversas dessas evocações da cor verde.

0 preto de seu apartamento e de seu vestuário podem fazer referência à morte, que ao menos no ocidente traz relação com a cor. Isso também é considerado quando se relaciona o preto ao noir. Quando Luca atira em Ugo, ele golpeia o rosto de Nelly com um soco e ela cai desmaiada sobre o tapete preto e branco, assim como Ugo (figura 8). 
Figura 8 - Fotograma de Ugo e da femme fatale, derrotados, sobre o tapete branco e preto, sugerindo já o destino do casal.

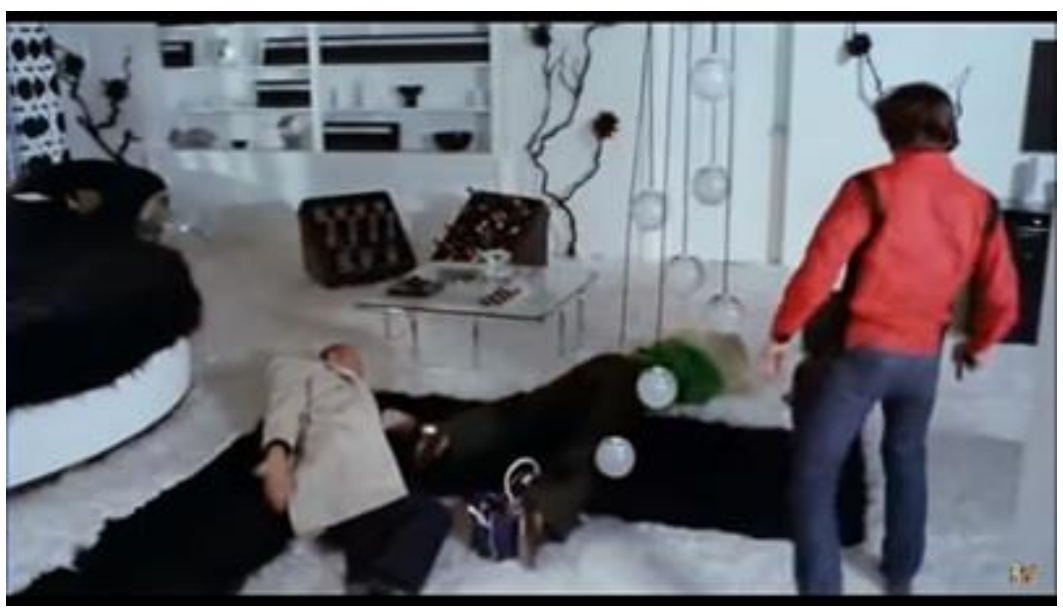

Fonte: Milano Calibro 9 (1972).

0 rosto de Nelly agora apresenta nova transfiguração: da beleza angelical para a desfiguração devido à violência e ao sangue decorrente (figura 9). Contrasta-se o sangue de ambos com o vermelho se evidenciando na superfície branca e macia do elegante tapete. Temos o contraste da morte fria, dura e suja, com o ambiente inicialmente limpo e confortável.

Figura 9 - Fotograma de Luca, tentando acordar a mulher amada, cujo sangue contrasta com o tapete alvo.

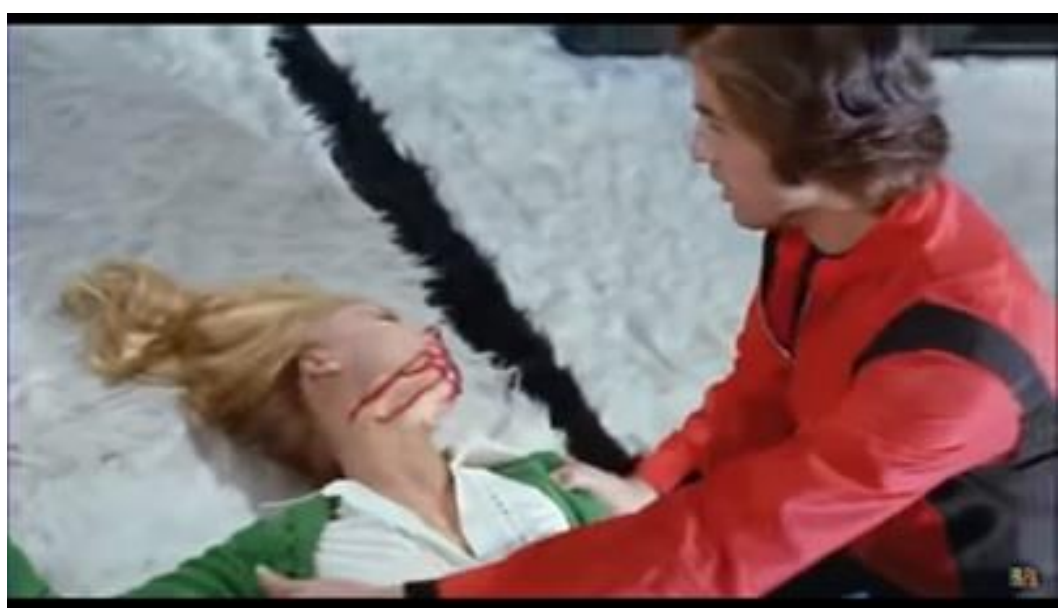

Fonte: Milano Calibro 9 (1972).

A violência típica do noir é bastante evidenciada nesta sequência de cenas, que abusa dos tiros, apresenta um forte soco no rosto de uma mulher, além de uma sequência de vários planos com uma personagem tendo a cabeça batida contra a quina de um móvel, o que 
sugere sua morte. Para além da violência simbólica, também responsável pelos danos psicológicos prováveis ou verificáveis em várias personagens, tem-se esta física, evidente, repetida, de teor incômodo devido aos planos muitas vezes fechados e ao sangue farto e vermelho, que a torna mais notória e intensa.

\section{Considerações finais}

Nelly implantara em Ugo o desejo de fugir para Beirute e gastar o dinheiro que acreditava estar com ele. Ao final, ele a convida para fazer exatamente isso, o que sugere uma correspondência ao desejo da femme fatale. 0 golpe dela funciona. Entretanto, ela é punida, ficando sem o dinheiro, pois a polícia o toma ao invadir o apartamento. Provavelmente será também comprometida pelos crimes de assassinato e talvez roubo do dinheiro, o que se evidencia no cenário do apartamento. Luca, ao que tudo indica, foi morto pelos golpes de Rocco e recairão sobre a femme fatale grandes responsabilidades.

Ainda sobre o destino do casal Nelly e Ugo, quando este vai buscá-la para fugir, ela o espera com uma armadilha. Ao fim, seu comparsa mata o protagonista, que a amava. 0 último ato do protagonista antes de morrer é dar um soco de vingança na mulher que amava, quando percebe a traição. Ela desmaia (aparentemente) com o rosto todo ensanguentado, deformando esteticamente a beleza e também tendo maculada a aura angelical/bondosa que apresentava fingidamente.

Ao final, temos, portanto, um protagonista punido com a vida, pelo envolvimento no crime e, principalmente, por ter cedido à sedução da femme fatale; e esta, que responde ao destino da femme fatale clássica, conforme apontado por Žižek (2009), já que é punida explicitamente. Não sobrevive materialmente, no sentido de que perde tanto os 30 milhões de liras do roubo planejado com Luca quanto os 300 mil dólares de Ugo, e de que provavelmente será presa pelos seus crimes. Temos um desfecho para a femme fatale que adequa o filme ao destino que usualmente é reservado a ela. Por fim, ressalta-se que a obra, não escapando ao que normalmente se observa nas narrativas fílmicas noir, trata a mulher a partir de uma perspectiva misógina, responsabilizando-a e punindo-a pelo seu envolvimento que prejudica as figuras masculinas, sobretudo o protagonista.

Percebe-se, na presente pesquisa, a contribuição essencial dos elementos concretos e visíveis de trabalho da direção de arte que são apontados na análise deste filme para sua composição visual. Devido ao recorte dado e as demais escolhas, não foi possível contemplar outros aspectos. Outros elementos relacionados à direção de arte poderiam ter sido 
observados, assim como de outros departamentos, como a fotografia ou mesmo de som. Enfim, descrições outras, com observações e interpretações diversas seriam possíveis. Entretanto, considera-se a suficiência da análise para apontar e permitir a reflexão sobre o modo como a femme fatale, em seu potencial hedonista, direciona as demais personagens e funciona como elemento fundamental para a condução da narrativa.

\section{Referências}

AUGUSTI, A. R. Cinema noir: as marcas da morte e do hedonismo na atualização do gênero. 2013. Tese (Doutorado em Comunicação Social) - Programa de Pós-Graduação em Comunicação Social, Pontifícia Universidade Católica do Rio Grande do Sul, Porto Alegre, 2013. Disponível em: https://tede2.pucrs.br/tede2/bitstream/tede/4520/1/TES_ALEXANDRE_ROSSATO_AUGUS TI_COMPLETO.pdf

AUMONT, J.; MARIE, M. A análise do filme. 2 ed., Lisboa: Texto e Grafia, 2004.

BAZIN, A. Le décor est un acteur. CinéClub, Fédération Française des Ciné-Clubs, n. 1, déc. 1949. p. 6-7.

BORDE, R.; CHAUMETON, E. Panorama del cine negro. Buenos Aires: Losange, 1958.

CAPRARA, V.; COZZOLINO, G. Cinema noir e neonoir italianos. [Entrevista concedida a Alexandre Augusti]. Napoli, 19 jan. 2016.

CHEVALIER, J.; GHEERBRANT, A. Dicionário de símbolos: mitos, sonhos, costumes, gestos, formas, figuras, cores, números. Rio de Janeiro: José Olympio, 1992.

FREZZA, L. Cinema noir e neonoir. [Entrevista concedida a Alexandre Augusti]. Fisciano, 16 maio. 2012.

HEREDERO, C. F.; SANTAMARINA, A. El cine negro: maduración y crisis de la escritura clásica. Barcelona: Paidós, 1996.

JACOB, E. M. Um lugar para ser visto: a direção de arte e a construção da paisagem no cinema. 2006. Dissertação (Mestrado em Comunicação, Imagem e Informação) - Curso de Pós-Graduação em Comunicação, Imagem e Informação, Universidade Federal Fluminense, Niterói, 2006.

JUNQUEIRA, T. Direção de arte em cinema: leituras de um espaço. In: BUTRUCE, D; BOUILLET, R. (org.). A direção de arte no cinema brasileiro. Rio de Janeiro: Caixa Cultural, 2017. p. 150-159.

LE JOUR se lève. Direção: Marcel Carné. Produção: Jean-Pierre Frogerais. Intérpretes: Jean Gabin, Jules Berry, Arletty et al. Roteiro: Jacques Viot, Jacques Prévert et al. [S.l.]: 
Productions Sigma. France, 1939, DVD (93 min), son., preto e branco. Título em português: Trágico amanhecer.

MATTOS, A. C. de G. de. 0 outro lado da noite: film noir. Rio de Janeiro: Rocco, 2001.

MILANO calibro 9. Direção: Fernando di Leo. Produção: Armando Novelli. Intérpretes: Gastone Moschin; Barbara Bouchet; Mario Adorf et al. Roteiro: Fernando di Leo. [S. l.]: Cineproduzioni Daunia 70. Italia, 1972, DVD (100 min), son., color.

ROSE, D. Análise de imagens em movimento. In: BAUER, M, W.; GASKELL, D. (org.). Pesquisa qualitativa com texto, imagem e som: um manual prático. 2. ed. Petrópolis, Vozes, 2002. p. 343-363.

SEGER, L. Como criar personagens inesquecíveis. São Paulo: Bossa Nova, 2006.

SILVER, A.; URSINI, J. Film noir. Lisboa: Taschen, 2004.

VANOYE, F.; GOLIOT-LÉTÉ, A. Ensaio sobre a análise fílmica. 6. ed. Campinas: Papirus, 1994.

VARGAS, G. P. Direção de arte: um estudo sobre sua contribuição na construção dos personagens Lígia, Kika e Wellington do filme Amarelo Manga. 2014. Dissertação (Mestrado em Comunicação Social) - Programa de Pós-Graduação da Faculdade de Comunicação Social, Pontifícia Universidade Católica do Rio Grande do Sul, Porto Alegre, 2014.

ŽIŽEK, S. Lacrimae rerum: ensaios sobre cinema moderno. São Paulo: Boitempo, 2009.

The hedonist perspective of the femme fatale element: the contribution of visuality in

building the Nelly Borden character in Milano Calibro 9

\begin{abstract}
This work aims, from the analysis of the movie Milano calibro 9, address the hedonistic perspective of Italian film noir. The element femme fatale is chosen as the central focus of observation. Priority is given to the visuality of the work, seeking more regularly the concrete and visible elements of art direction work. The analysis is conducted by a methodological construction understood from some assumptions of film analysis, highlighting the authors Jacques Aumont \& Michel Marie, Francis Vanoye \& Anne Goliot-Lété, and the methodological proposition of Diane Rose. This research allows us to point out and reflect on how the femme fatale, in its hedonistic potential, directs the other characters and works as a fundamental element for the conduction of the narrative.
\end{abstract}




\section{Keywords}

Film analysis. Italian film noir. Art direction. Femme fatale.

Hedonism.

\section{Autoria para correspondência}

Alexandre Rossato Augusti

alexandreaugusti@unipampa.edu.br

Gilka Padilha de Vargas

gilkavargas@gmail.com

\section{Como citar}

AUGUSTI, Alexandre Rossato; VARGAS, Gilka Padilha de. A perspectiva hedonista do elemento femme fatale: a contribuição da visualidade na construção da personagem Nelly Borden em Milano Calibro 9. Intexto, Porto Alegre, n. 52, e-107455, jan./dez. 2021. DOI: http://dx.doi.org/10.19132/18078583202152.107455

Recebido em 11/09/2020

Aceito em 09/03/2021 